The International Journal of Indian Psychology: Volume: 01 | Issue: 04 No. 2 | ISSN 2348-5396

\title{
Sports for Positive Mental Health: A Comparative Study of Mental Health among Individual Athletes, Team Athletes And Non-Athletes
}

\author{
Dr. Milan P. Patel*, Mr. Ankur D. Chaudhari**
}

\begin{abstract}
Mental Health affects our ability to make the most of the opportunities that come our way and play a full part amongst our family, workplace, community and friends. It's also closely linked with our physical health. Whether we call it well-being, emotional welfare or mental health, it's key to living a fulfilling life.

The purpose of the study was to compare the Mental Health status among Individual Athletes, Team Athletes and Non-Athletes. Purposive sampling was done in which subjects for the present study were 148 male students of Navsari Agricultural University, Navsari studying various courses in the academic year 2013-14. The Mental Health Scale prepared by Dr .D .J.Bhatt and Ms. Geeta R. Geedawas used as a tool for the present study.

The scores arrived from 45 Individual Athletes, 51 Team Athletes and 52 Non-Athletes were compared by applying the ' $\mathrm{F}$ ' test. The resultant value 7.566 was found significant at the predetermined confidence level of 0.5 . Further, this study revealed significant difference between the mean score of Team Athlete \& Non-Athlete, whereas there was no significant difference between the Individual Athlete \& Team Athlete and that of Individual Athlete \& Non-Athlete. Thus it was evident that Mental Health of Team Athlete was significantly better in comparison to Individual Athlete and Non-Athlete. This clearly shows that those who participate in team games have more chances to stay mentally fit as they involve themselves in preparing mentally for various team competitions. Mental Health is considered to be one of the important components of daily life style. This is certainly an important factor for all of us to live better and longer life. Thus, we all should daily participate in physical activity to stay physically and mentally fit.
\end{abstract}

KEYWORDS: Mental Health, Individual Athletes, Team Athletes, Non-Athletes.

*Physical Instructor, College of Veterinary Science and A.H., Navsari Agricultural University, Navsari, Gujarat

**Physical Instructor, N.M. College of Agriculture, Navsari Agricultural University, Navsari, Gujarat 
The International Journal of Indian Psychology: Volume: 01 | Issue: 04 No. 2 | ISSN 2348-5396

\section{INTRODUCTION}

Mental Health affects us all. How we think and feel about ourselves and our lives impacts on our behavior and how we cope in tough times. It affects our ability to make the most of the opportunities that come our way and play a full part amongst our family, workplace, community and friends. It's also closely linked with our physical health. Whether we call it well-being, emotional welfare or mental health, it's key to living a fulfilling life.

We all have times when we feel down or stressed or frightened. Most of the time those feelings pass. But sometimes they develop into a more serious problem and that could happen to any one of us. One may bounce back from a setback while someone else may feel weighed down by it for a long time. Mental health doesn't always stay the same. It can change as circumstances change and as you move through different stages of your life.

Mental health is vital for individuals, families and communities, and is more than simply the absence of a mental disorder. Mental health is defined by the World Health Organization (October 2011) as 'a state of well-being in which every individual realizes his or her own potential, can cope with the normal stresses of life, can work productively and fruitfully, and is able to make a contribution to her or his community.'. The positive dimension of mental health is stressed in whose definition of health as contained in its constitution: "Health is a state of complete physical, mental and social well-being and not merely the absence of disease or infirmity."

In a book en titled mental hygiene in public health P.V. Lewkan has written that mentally healthy individualizing who is himself satisfied, lives peacefully with his neighbors, makes healthy citizen his children and even after per forming these fundamentals duties has enough energy left to do something of benefit to society. Possessing mental health, an individual can adjust properly to his environment, and can make the bested fort for his own, his family's and his society's progress and betterment. The chief characteristic of mental health is adjustment. The greater the degree of successful adjustment the greater will be the mental health of the in dividable. 
The International Journal of Indian Psychology: Volume: 01 | Issue: 04 No. 2 | ISSN 2348-5396

\section{Mental Health Facts}

- 1 out of every 5 young people suffers from some form of diagnosable mental illness.

- About $19 \%$ of young people contemplate or attempt suicide each year.

- Suicide is the third leading cause of death among people ages 15-24, and the second leading cause of death in college students ages 20-24.

- Over $66 \%$ of young people with a substance use disorder have a co-occurring mental health problem.

- Over 2/3 of young people do not talk about or seek help for mental health problems.

- $44 \%$ of American college students reported feeling symptoms of depression.

- From 1980-1986, the suicide rate for African-American males ages 15-19 increased more than $100 \%$.

- $80-90 \%$ of people that seek the necessary form of mental health treatment can function the way they used to.

- Stereotypes are one of the largest barriers preventing young people from seeking the help they need.

- An estimated 5 million young females suffer from eating disorders each year and eating disorders are the deadliest mental illness claiming more lives than any other illness.

\section{Benefits of Sports Participation For Developing Mental Health}

\section{Anxiety Reduction}

Anxiety is associated with the emergence of a negative form of cognitive appraisal typified by worry, self-doubt, and apprehension. According to Lazarus and Cohen (1977), it usually arises "...in the face of demands that tax or exceed the resources of the system or ... demands to which there are no readily available or automatic adaptive responses".

Anxiety is a cognitive phenomenon and is usually measured by questionnaire instruments. These questionnaires are sometimes accompanied by physiological measures that are associated with heightened arousal/anxiety (e.g., heart rate, blood pressure, skin conductance, muscle tension).

Landers and Petruzzello (1994) examined the results of 27 narrative reviews that had been conducted between 1960 and 1991 and found that in $81 \%$ of them the authors had concluded that physical activity/fitness was related to anxiety reduction following exercise and there was little or no conflicting data presented in these reviews. For the other 19\%, the authors had concluded that most of the findings were supportive of 
exercise being related to a reduction in anxiety, but there were some divergent results. None of these narrative reviews concluded that there was no relationship.

There have been six meta-analyses examining the relationship between exercise and anxiety reduction. All six of these meta-analyses found that across all studies examined, exercise was significantly related to a reduction in anxiety. These effects ranged from "small" to "moderate" in size and were consistent for trait, state, and psycho-physiological measures of anxiety.

The exercise can produce an anxiety reduction similar in magnitude to other commonly employed anxiety treatments is noteworthy since exercise can be considered at least as good as other techniques, in addition it has many other physical benefits.

\section{Depression}

Depression is a prevalent problem in today's society. Clinical depression affects $2-5 \%$ of Americans each year (Kessler et al., 1994) and it is estimated that patients suffering from clinical depression make up 6-8\% of general medical practices (Katon\&Schulberg, 1992).

\section{Exercise produces larger antidepressant effects when:}

- The exercise training program was longer than nine weeks and involved more sessions (Craft, 1997; North et al., 1990);

- Exercise was of longer duration, higher intensity, and performed a greater number of days per week (Craft, 1997);

- Subjects were classified as medical rehabilitation patients (North et al., 1991) and, based on questionnaire instruments, were classified as moderately/severely depressed compared to mildly/moderately depressed (Craft, 1997).

The meta-analyses are inconsistent when comparing exercise to the more traditional treatments for depression, such as psychotherapy and behavioral interventions (e.g., relaxation, meditation), and this may be related to the types of subjects employed.

For clinically depressed people exercise produces the same effects as psychotherapy, behavioral interventions, and social contact. Exercise used in combination with individual psychotherapy or exercise together with drug therapy gives better results.

That exercise is effective traditional therapy to encourage, especially considering the time and cost involved with treatments like psychotherapy. Exercise may be a positive adjunct for the treatment of depression since exercise provides additional health benefits (e.g., increase in muscle tone and decreased incidence of heart disease and obesity) that 
behavioral interventions do not. Thus, since exercise is cost effective, has positive health benefits, and is effective in alleviating depression, it is a viable adjunct or alternative to many of the more traditional therapies. Future research also needs to examine the possibility of systematically lowering antidepressant medication dosages while concurrently supplementing treatment with exercise.

\section{Positive Mood}

A mood is defined as a feeling, state or prolonged emotion that influences the whole of one's psychic life. It can also relate to passion or feeling. Mood can and does affect perceived health, personal confidence, one's perceptions of the world around us and our actions based on those perceptions. Moods may signify happiness, anger, tension, or anxiety.

Numerous studies have reported positive mood benefits from exercise. Moodenhancing effects have been evidenced in many different physical activities, including jogging, swimming, yoga, and weight lifting (Berger and Owen, 1988). In their extensive review of the salient literature, Berger emphasized that mood enhancement is dependent upon interactions between participant, exercise modality and practice conditions; and made several recommendations for structuring an exercise session to maximize mood enhancement. They suggested that activities should be non-competitive, rhythmic, and predictable, should last for at least 20 - 30 minutes, and should be moderately intense.

\section{Self-Esteem}

Self esteem is defined by the degree worth and competence that we attribute to ourselves. Self-esteem is the feeling of self-worth that determines how valuable and competent we feel. Through sport, we can enhance our self esteem by having a positive image of our bodies and the physical skills and abilities that we develop. We feel positive self worth through the recognition that we receive from family and friends and the social relationships that develop as a result of our involvement in sport and physical activity. Yet, we may be vulnerable to low self esteem in sport and physical activity if we perceive our body to be inadequate, unfit or inappropriate for our selected activity. We may feel that our self-worth is judged on our losses and wins versus our abilities and intentions. The intensive participation in sport may lead to social isolation and lack of family 
The International Journal of Indian Psychology: Volume: 01 | Issue: 04 No. 2 | ISSN 2348-5396

support. All of these negative emotions need to be refocused in order to build positive self-esteem.

\section{Restful Sleep}

Sleep is a complex physiological process that scientists are only just beginning to understand. We do know that when you are asleep, there is a clear alteration in the activity of the brain. There are also changes in the levels of some hormones, for example, growth hormone is released during the deeper stages of sleep. Sleep is described as a highly restorative process.

It is also well-know that exercise has a profound impact upon sleep. Up to a point, the more you ask your body to do in the day, the more sleep is required to recover. This is why endurance athletes in particular generally need more sleep. However, excessive exercise can actually disrupt sleep, so it is important to strike a balance.

Recent research has shown that Rapid Eye Movement (REM) sleep, which is the deepest stage of sleep but where the brain is most active, is essential for improving memory and learning, so this could be crucial for athletes learning complex tasks. 'Power naps' may also be effective in restoring mental alertness, although these do not offer the same restorative benefits as sleeping at night.

\section{WHAT RESEARCH SAYS?}

\section{No sports - no mental health? Analysis of longitudinal effects in Sports and Health Program (SPH) data}

Results from the Zurich (2003) study have shown lasting associations between sport practice and mental health. The effects are pronounced in people with pre-excising mental health problems. The analysis covered the interviews and included 3891 stayers, i.e., participants who were interviewed. The outcome variables are depression / blues / anxiety, weakness / weariness, sleeping problems, energy / optimism. About $60 \%$ of the SHP participants practice weekly or daily an individual or a team sport. A similar proportion enjoys a frequent physical activity (for half an hour minimum) which makes oneself slightly breathless. Practice of sport is clearly interrelated with self-reported depressive symptoms, optimism and weakness. Moreover, direct interrelations commonly led to better fits than models with lagged variables, thus indicating that 
The International Journal of Indian Psychology: Volume: 01 | Issue: 04 No. 2 | ISSN 2348-5396

delayed effects of sport practice on the self-reported psychological complaints are less important. Lack of sport practice is a marker for serious psychological symptoms and mental disorders.

\section{Mental health improved by 20 minutes of physical activity (2008)}

A study by Thompson (2008) Being physically active once a week for 20 minutes is enough to boost mental health, according to a cross-sectional study, but there is lack of consensus regarding the optimal amount and type of activity to achieve these benefits. Researchers used the 12-item General Health Questionnaire (GHQ-12) to examine the association of different types and amounts of physical activity with current mental health. Researchers surveyed nearly 20000 Scottish adults to determine their level of psychological distress and self-reported frequency of physical activity including sports, walking and domestic activity. At least one 20-minute session a week of any type of activity was associated with lower risk of psychological distress. For sports and all activity types combined, risk reductions increased as the frequency of activity increased.

Who Fact files says that about half of mental disorders begin before the age of 14 . Around $20 \%$ of the world's children and adolescents are estimated to have mental disorders or problems, with similar types of disorders being reported across cultures. Yet, regions of the world with the highest percentage of population under the age of 19 have the poorest level of mental health resources. Most low- and middle-income countries have only one child psychiatrist for every 1 to 4 million people.

\section{PURPOSE OF THE STUDY}

The purpose of the study was to compare the Mental Health status among Individual Athletes, Team Athletes and Non-Athletes.

\section{HYPOTHESIS}

It was hypothesized that there will be no significant difference in Mental Health among Individual Athletes, Team Athletes and Non-Athletes.

\section{METHODOLOGY}

Sample: Purposive sampling was done in which subjects for the present study were 148 male students of Navsari Agricultural University, Navsari studying various courses in the academic year 2013-14. These subjects were divided into three groups based on their participation in activity i.e. Individual Athletes, Team Athletes and Non-Athletes.
(C) 2014 www.ijip.in
July-September 2014
$40 \mid \mathrm{P}$ a g e 
The International Journal of Indian Psychology: Volume: 01 | Issue: 04 No. 2 | ISSN 2348-5396

Tool: The Mental Health Scale prepared by Dr. D. J. Bhatt and Ms .Geeta R. Geeda was used as a tool for the present study. This scale contains 40 statements pertaining to five do mains aim of mental health, these five dimensions in clued perception of reality, integration of personality, positive self-evaluation, group oriented attitudes and environmental mastery to beratedon3- point scale.

Analysis: The scores arrived from 45 Individual Athletes, 51 Team Athletes and 52 NonAthletes were compared by applying the ' $F$ ' test. The resultant value is shown in the table below:

Table - 1, Significant difference of mental health among individual athletes, Team athletes and non-athletes

\begin{tabular}{|l|c|c|c|c|c|}
\hline & $\begin{array}{c}\text { Sum of } \\
\text { Squares }\end{array}$ & df & $\begin{array}{c}\text { Mean } \\
\text { Square }\end{array}$ & F & Sig. \\
\cline { 1 - 4 } Between Groups & 1704.832 & 2 & 852.416 & $7.566^{*}$ & .001 \\
\hline Within Groups & 16335.675 & 145 & 112.660 & & \\
\hline Total & 18040.507 & 147 & & & \\
\hline
\end{tabular}

It is evident from the table 1 that there was a significant difference in Mental Health male subjects aged 18 to 25 years among Individual Athletes, Team Athletes and Non-Athletes, as they obtained $F$ value (7.566) is greater than the tabulated $F$ value (3.06) which is required to be significant at .05 level with $(2,145)$ degree of freedom.

As the F-Ratio was found significant in case of Mental Health the Schaffer's Test PostHock was applied to test the significant difference between the means of Individual Athletes, Team Athletes and Non-Athletes. The results pertaining to this are presented in Table-2.

Table - 2, Table of multiple comparisons of mental health among individual athletes, team athletes and non-athletes

\begin{tabular}{|l|l|l|l|l|}
\hline (I) Group & $(\mathbf{J})$ Group & $\begin{array}{l}\text { Mean } \\
\text { Difference (I-J) }\end{array}$ & Std. Error & Sig. \\
\hline $\begin{array}{l}\text { Individual } \\
\text { Athletes }\end{array}$ & Team Athletes & -4.31634 & 2.17084 & .142 \\
\cline { 2 - 5 } Team Athletes & Non-Athletes & 3.81752 & 2.16104 & .214 \\
& $\begin{array}{l}\text { Individual } \\
\text { Athletes }\end{array}$ & 4.31634 & 2.17084 & .142 \\
\cline { 2 - 5 } & Non-Athletes & $8.13386^{*}$ & 2.09178 & .001 \\
\hline \multirow{2}{*}{ Non-Athletes } & $\begin{array}{l}\text { Individual } \\
\text { Athletes }\end{array}$ & -3.81752 & 2.16104 & .214 \\
\cline { 2 - 5 } & Team Athletes & $-8.13386^{*}$ & 2.09178 & .001 \\
\hline
\end{tabular}

* The mean difference is significant at the .05 level.
(C) 2014 www.ijip.in
July-September 2014
$41 \mid \mathrm{P}$ a g e 
The International Journal of Indian Psychology: Volume: 01 | Issue: 04 No. 2 | ISSN 2348-5396

It is evident from the Table-2 that there was a Significant Difference between the mean score of Team Athlete \& Non-Athlete, whereas there was no Significant Difference between the Individual Athlete \& Team Athlete and that of Individual Athlete \& Non-Athlete. Thus it was evident that Mental Health of Team Athlete was significantly better in comparison to Individual Athlete and Non-Athlete.

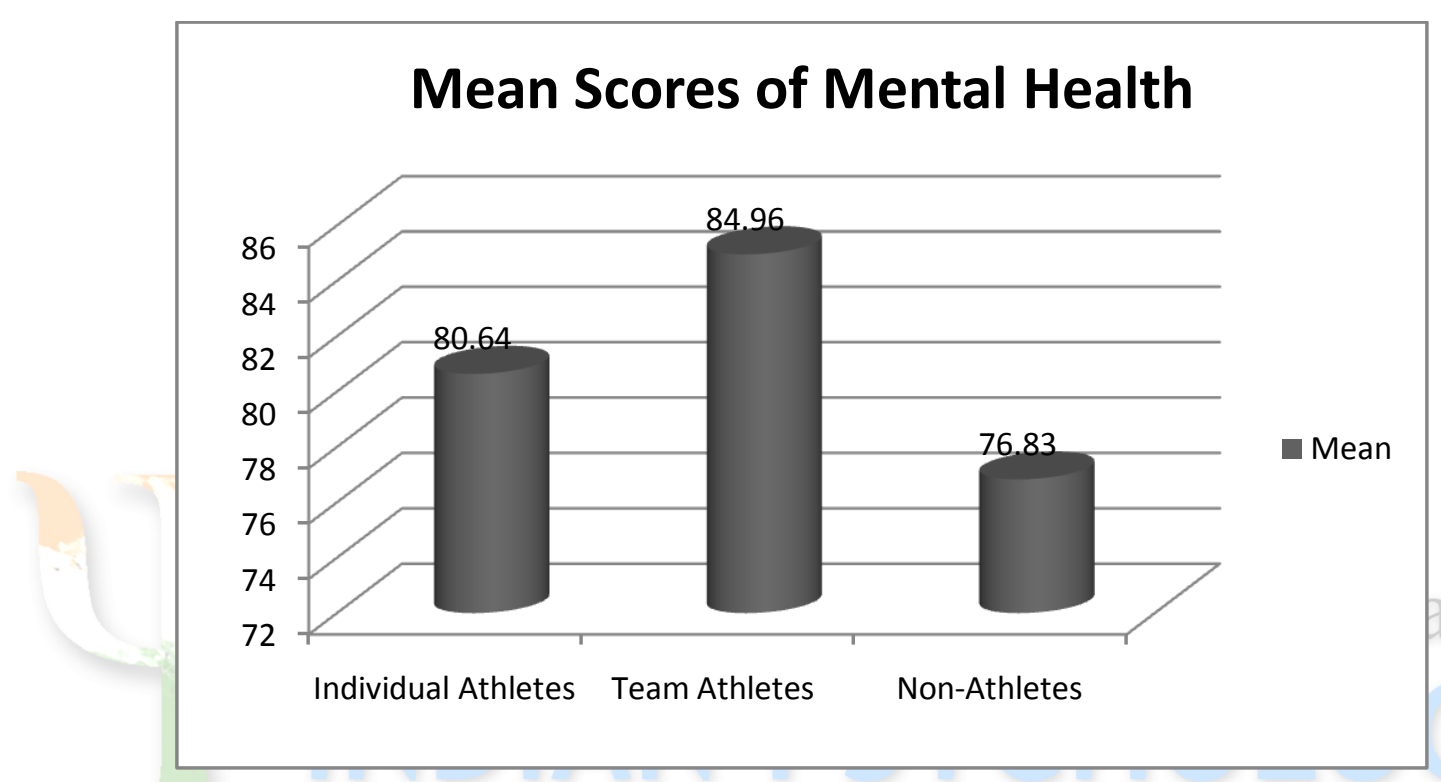

\section{Graph 1: Graphical Representation of Mean Scores of Mental Health among Individual Athletes, Team Athletes and Non-Athletes}

\section{CONCLUSION}

On the basis of the findings of the present study the following conclusion was drawn:

This study revealed significant difference between the mean score of Team Athlete \& Non-Athlete, whereas there was no significant difference between the Individual Athlete \& Team Athlete and that of Individual Athlete \& Non-Athlete. Thus it was evident that Mental Health of Team Athlete was significantly better in comparison to Individual Athlete and NonAthlete. This clearly shows that those who participate in team games have more chances to stay mentally fit as they involve themselves in preparing mentally for various team competitions. 
The International Journal of Indian Psychology: Volume: 01 | Issue: 04 No. 2 | ISSN 2348-5396

Mental Health is considered to be one of the important components of daily life style. This is certainly an important factor for all of us to live better and longer life.Thus, we all should daily participate in physical activity to stay physically and mentally fit.

Neither mental nor physical health can exist alone. Mental, physical and social functioning is interdependent. Participation in sports is related to positive mental health as indicated by the present study. Sports programs should be first-line methods for improving mental health among the youth. Access to sports programs can also be a primary method to improve the lives of people who may still be experiencing poor mental health.

\section{REFERENCES}

1. Fahey, Thomas D., Insel, Paul M. and Roth, Walton T., Fit and Well, California: Mayfield Publishing Company, 1994.

2. Finley, Guy, Freedom from the Self-punishing Thoughts, Delhi: PustakMahal, 1998.

3. Greenberg, Jerrold S. and Pargram, David, Physical Fitness A Wellness Approach, New Jersey: Prentice-Hall Inc. Englewood Cliffs, 1986.

4. Heflinger, Craig Anne, and Nixon, Carol T., Families and The Mental Health System For Children and Adolescents, New Delhi: Sage Publications, 1996.

5. The 6th Global Conference on Health Promotion in Bangkok, Thailand, 11 August 2005.

6. The United Nations Educational, Scientific and Cultural Organization (UNESCO) Charter (1978), Paris. 